\title{
"É um malabarismo com vários pratos ao mesmo tempo!": o trabalho docente em universidades públicas
}

\author{
"It's a juggling with several dishes at the same \\ time!": teaching work in public universities
}

\author{
Iana Vasconcelos ${ }^{a}$ \\ (1) https://orcid.org/0000-0003-3049-0445 \\ Rita de Lourdes de Lima \\ (D) https://orcid.org/0000-0002-7920-115X
}

Resumo: Este artigo apresenta parte dos resultados de pesquisa que objetivou analisar as condições do trabalho docente nos cursos de Serviço Social de universidades públicas do Rio Grande do Norte. Nessa perspectiva, analisa os impactos da contrarreforma do Estado na política educacional e suas expressões no contexto investigado. Os resultados evidenciam que o trabalho docente se efetiva em meio a condições adversas e sobrecarga de trabalho, submergindo tempo de descanso e até momentos de adoecimento.

Palavras-chave: Trabalho docente. Serviço Social. Universidade pública.

\begin{abstract}
This article presents part of the research results that aimed to analyze the conditions of teaching work in Social Work courses of public universities of Rio Grande do Norte. In this perspective, we analyze the impacts of the State counter-reform on educational policy and its expressions in the investigated context. The results show that teaching work goes in the midst of adverse conditions and work overload, submerging rest times and even moments of illness.
\end{abstract}

Keywords: Teaching work. Social Work. Public university. 


\section{Introdução}

nalisar o trabalho docente no atual contexto brasileiro requer
compreender a política educacional, na qual incidem os influxos
da reestruturação do capital que, com vistas a enfrentar mais uma de suas crises cíclicas, deflagra formas de intensificação da exploração da força de trabalho, concomitante à implementação de uma contrarreforma ${ }^{1}$ do Estado, de cunho neoliberal, acirrada no período mais recente.

Neste artigo, enfatizaremos as expressões desse processo na educação superior, explicitando suas decorrências no trabalho docente em universidades públicas. As análises construídas se fundamentam em dados produzidos por meio de uma pesquisa ${ }^{2}$ qualitativa, pautada no método crítico-dialético, cujo percurso metodológico incluiu revisão bibliográfica e aplicação de questionários e entrevistas semiestruturadas com dezesseis assistentes sociais docentes do quadro permanente dos programas de pós-graduação stricto sensu da Universidade Federal do Rio Grande do Norte (UFRN) ${ }^{3}$ e Universidade do Estado do Rio Grande do Norte (UERN), ${ }^{4}$ as duas instituições públicas que contemplam a formação acadêmica nesta área no referido estado.

1 Considerando o caráter regressivo e destrutivo da denominada "reforma do Estado" encampada a partir dos anos 1990 no tocante às conquistas democráticas e aos direitos sociais, estando, assim, na contramão do sentido ao termo reforma, incorporamos sua denominação como contrarreforma, inspirando-nos em autores como Behring (2003).

2 A citada pesquisa intitulada "Trabalho docente e saúde-adoecimento nos cursos de Serviço Social das universidades públicas do Rio Grande do Norte" integrou o estágio pós-doutoral realizado no período de setembro de 2018 a agosto de 2019 no Programa de Pós-Graduação em Serviço Social da Universidade Federal do Rio Grande do Norte.

3 O Programa de Pós-Graduação em Serviço Social (PPGSS) da UFRN foi criado em 2000 (com o curso de mestrado acadêmico) e a partir de 2016 passou a ofertar o curso de doutorado. Atualmente (dez./2019), existem 38 estudantes vinculados(as) a esse programa, sendo dezenove em cada nível de formação. Dezenove docentes participam desse programa, sendo quinze no quadro permanente. Entre estes, nove são assistentes sociais, das quais sete integram os sujeitos da pesquisa.

4 O Programa de Pós-graduação em Serviço Social e Direitos Sociais (PPGSSDS) da UERN foi criado em 2014, com o curso de mestrado acadêmico, estando atualmente (dez./2019) com 34 
Ainda no tocante à pesquisa, todas as participantes são mulheres, com contratos efetivos e jornada de quarenta horas com dedicação exclusiva. Cinco participantes informaram estar em cargos administrativos (chefia do departamento, direção da faculdade ou coordenação de programa de pós-graduação). Registraram-se duas docentes com bolsas de produtividade do CNPq. ${ }^{5}$ Em geral, acumulam vários anos de trabalho e exercem o trabalho docente há bastante tempo, havendo uma parcela atualmente aposentada (quatro), que no momento da pesquisa trabalhava havia mais de trinta anos nessa atividade; enquanto seis acumulam de 21 a 30 anos de trabalho docente e as outras seis exercem a docência há um período entre onze e vinte anos.

Na expectativa de contribuir para análise crítica acerca das particularidades e desafios do trabalho docente, dividimos nossa exposição a seguir em dois itens: a) Reestruturação capitalista, contrarreforma do Estado e ensino superior no Brasil - nele apresentamos considerações sobre o Estado brasileiro e o ensino superior na conjuntura atual —; b) Condições de trabalho e sobrecarga docente - aqui discutimos os influxos do produtivismo nas universidades potiguares, nos detendo mais especificamente no cotidiano do trabalho docente.

\section{Reestruturação capitalista, contrarreforma do Estado e ensino superior no Brasil}

Partimos da perspectiva que o sistema capitalista se assenta na exploração e alienação da força de trabalho, de tal modo que as relações antagônicas entre as classes sociais são inerentes a esse modelo

mestrandos(as). É constituído por doze docentes, sendo onze assistentes sociais pertencentes ao quadro permanente. Nesta pesquisa, obtivemos a participação de nove dessas professoras.

5 O Conselho Nacional de Desenvolvimento Científico e Tecnológico (CNPq) lança anualmente edital para que os(as) docentes concorram a bolsas de produtividade, que é um incentivo do CNPq para docentes considerados produtivos. 
societário, bem como suas crises cíclicas, para as quais são implementadas medidas voltadas para a recomposição da sua reprodução. De tal modo, a reestruturação capitalista se configura um conjunto de mecanismos deflagrados com vistas ao enfrentamento de mais um ciclo da reincidente crise estrutural do capital, difundida mundialmente desde meados da década de 1970. O processo de reestruturação capitalista se instala no contexto brasileiro a partir dos anos 1990, o qual, segundo Netto e Braz (2006), compõe-se de estratégias articuladas sobre o tripé: reestruturação produtiva, ${ }^{6}$ financeirização e ideologia neoliberal. Vale ressaltar que "o predomínio da financeirização sob o capitalismo mundial tende a incrementar a velocidade, a intensidade e amplitude do ser-precisamente-assim do capital, propiciando um salto qualitativo em seu potencial ofensivo sobre o trabalho assalariado" (Alves, 2000, p. 26).

Esse processo de reestruturação capitalista, de viés neoliberal, introduzido na realidade brasileira a partir da gestão presidencial de Fernando Collor de Mello (1990-92), passou a ser disseminado mais sistematicamente no governo de Fernando Henrique Cardoso (FHC - 1995-2003), com a implementação do Plano Diretor da Reforma do Estado (1995).

Na sequência, os governos Lula da Silva (2003-11) e Dilma Rousseff (2011-16), embora tenham assumido uma face mais popular, mantendo alguns compromissos com os segmentos trabalhadores, não romperam com essa versão do Estado capitalista neoliberal. Isso porque estiveram pautados em uma suposta - e irrealizável - conciliação de classes, fadada ao fracasso, pois o antagonismo entre as classes sociais, cujos interesses são inconciliáveis, é algo estruturante e ineliminável ao sistema capitalista (Mustafa, 2018).

6 A reestruturação produtiva altera os modelos de gestão e de organização dos processos de trabalho, visando intensificar a produtividade e reduzir custos, pelo incremento dos recursos tecnológicos, redução das garantias legais e cooptação da subjetividade dos trabalhadores (Netto; Braz, 2006). 
Vale salientar que o processo de desmonte dos direitos sociais vem ocorrendo de forma aprofundada a partir do governo Michel $\mathrm{Temer}^{7}$ (2016-19), o qual efetuou a "reforma" trabalhista e deixou, como uma das expressões mais severas da política de austeridade encampada na sua gestão, a Emenda Constitucional (EC) 55, aprovada pelo Senado em 13/12/2016. "Essa mudança constitucional instituiu um Novo Regime Fiscal (NRF) no país e que prevalecerá, inicialmente, por 20 anos (portanto, até 2036), que congelará as despesas primárias e liberará os pagamentos relativos ao mercado financeiro" (Lima; Lima, 2019, p. 48). Expressa, portanto, o aprofundamento da contrarreforma do Estado, mediante diminuição da sua atuação na efetivação de políticas sociais universais.

Mais recentemente, na atual gestão presidencial de Jair Bolsonaro (2019-), as medidas regressivas se intensificaram e apareceram ainda mais escancaradamente, a exemplo da perversa "reforma" da Previdência recentemente aprovada, ${ }^{8}$ dos cortes anunciados para a educação, ${ }^{9}$ assim como do reforço às parcerias público-privado contidas no programa Future-se, ${ }^{10}$ proposto para as universidades e institutos federais.

7 Michel Temer foi eleito como vice-presidente para o mandato junto com Dilma Rousseff, pelo período de 2015 a 2018. Com o impeachment da presidenta, Temer assume o mandato, permanecendo no cargo até janeiro de 2019, quando toma posse o atual presidente eleito, Jair Bolsonaro (2019-).

8 O Congresso Federal promulgou no dia 12 de novembro de 2019 a reforma da Previdência. Para mais detalhes, ver: G1 Economia, 2019.

9 O atual ministro da Educação, Abraham Weintraub, anunciou, em 2 de maio de 2019, um corte de $30 \%$ dos recursos para universidades e institutos federais. Na UFRN, o corte será de cerca de R\$59 milhões, de acordo com o pró-reitor adjunto de Planejamento. O valor contingenciado atinge principalmente as áreas de custeio e investimento da instituição. Ressalte-se que a assistência estudantil não sofreu cortes (Jácome, 2019).

10 No dia 17 de julho de 2019, o governo federal, por intermédio do ministro da Educação, lançou o Future-se. O projeto propõe a entrada da iniciativa privada nas universidades federais e a redução da participação do governo no financiamento das universidades e institutos federais. O projeto enfrenta enormes resistências das universidades e institutos. No dia 18 de outubro de 2019, o governo anunciou mudanças na proposta original e lançou-a a nova consulta pública. A nova versão cita a "obediência à autonomia universitária" e abandona ideias como permitir que hospitais universitários cobrem pelo atendimento a pessoas com plano de saúde privado (cf. Moreno, 2019; Ilhéu, 2019; e Estadão, 2019. 
Analisar o trabalho docente requer evidenciar que em tempos de contrarreforma do Estado as universidades públicas têm sido negligenciadas no tangente ao seu financiamento estatal e submetidas, de formas diversificadas, à lógica do mercado, cujos rebatimentos impelem a precarização e a intensificação do trabalho docente sem considerar as especificidades do ensino superior. Segundo Chaui, a denominada "Reforma" do Estado se assenta no pressuposto ideológico de que este é responsável por todos os malefícios econômicos, sociais e políticos existentes, os quais seriam solucionados pela presença do mercado, tido como "portador de racionalidade sociopolítica e agente principal do bem-estar da República" (Chaui, 2001, p. 176). Dessa forma, "a Reforma encolhe o espaço público democrático dos direitos e amplia o espaço privado não só ali onde isso seria previsível - nas atividades ligadas à produção econômica -, mas também onde não é admissível - no campo dos direitos sociais conquistados". (Idem, p. 177).

Nesse sentido, a reestruturação do capital dissemina mudanças no mundo trabalho pautadas no modelo de acumulação flexível, concomitante à contrarreforma do Estado, as quais reverberam de forma regressiva nas condições de vida, trabalho e saúde dos diversos segmentos da classe trabalhadora. Tal processo se espraia no âmbito das instituições de ensino e afeta o trabalho docente. Segundo Forattini e Lucena (2015, p. 33),

Os parâmetros que a sociedade capitalista estabeleceu para os formadores de ciências e educadores são os mesmos para os processos produtivos, ou seja, metas quantitativas, produtivismo atrelado à ascensão na carreira, avaliação de resultados como método de reconhecimento e remuneração além de estrutura precária e massificada de políticas e práticas de ensino.

As expressões desses processos nas universidades públicas podem ser observadas nos comentários de uma entrevistada ao destacar que os(as) docentes lidam com elevadas exigências e vivem em função de um tempo muito acelerado. 
Tem um perfil do professor de excelência que não se consegue atingir, em função desse conjunto de demandas que envolvem a atividade docente. Então, eu não posso criar um pesquisador A1 nessas condições. [...] Se tenta construir um perfil novo de universidade, muito parecido com uma empresa e nós somos funcionários dessa empresa que têm que produzir, produzir, produzir... procurar revistas, procurar encontros... (Entrevista 8)

Dessa forma, atualmente, além de comumente lidarem com adversidades em termos de infraestrutura e materiais para a consecução do trabalho, os(as) docentes têm se deparado com exigências crescentes que induzem a necessidade de trabalhar cada vez mais para alcançar alta produtividade e, assim, possibilitar uma boa avaliação do seu curso (necessária inclusive para garantir a continuidade deste), além de concorrer a editais de fomento (para viabilizar acesso a recursos para infraestrutura, equipamentos, bem como para acesso a bolsas, incluindo a de produtividade), uma vez que os recursos se destinam, prioritariamente, àqueles(as) que comprovarem maior produção. Tal processo traz impactos na qualidade do seu trabalho, pois "conhecimento crítico e autônomo só se constrói com tempo e recursos e, nesse sentido, não se concebe uma formação de ensino superior submetida à lógica do custo-benefício, da competividade e do aligeiramento e que é obrigada a mendigar recursos para suas pesquisas no mercado" (Lima, 2016, p. 271).

Concomitantemente, deflagra-se uma forte ofensiva voltada para a restrição da autonomia no trabalho docente, sob a alegação de que é necessário suprimir a questão ideológica (ou a suposta "ameaça comunista") disseminada nas universidades. Isso porque a formação crítica é tida como uma forte ameaça à continuidade desse modelo societário da dominação e exploração. A este respeito, uma entrevistada ressalta:

[...] nessa conjuntura a universidade está sendo ameaçada não só de cortes financeiros, mas principalmente no sentido da liberdade de cátedra, né? De um patrulhamento ideológico e político que não pode eh... ser efetivado no âmbito das universidades públicas e nem privadas, né? O docente, ele 
tem que ter uma liberdade na exposição do seu conteúdo e do seu próprio pensamento. (Entrevista 7)

Segundo a mesma docente, a sala de aula deve ser um espaço de liberdade (docente e discente), o que não deve ser confundido com doutrinação ideológica, pois se trata de compromisso da universidade com a formação de um sujeito crítico. Diante dessa ofensiva de restrição da liberdade de cátedra, sustentada por propostas como o projeto "escola sem partido" (ou "lei da mordaça", como é alcunhada pelos(as) que o criticam - com os(as) quais concordamos), é importante o esclarecimento do Conselho Federal de Serviço Social (CFESS, 2018):

Esse projeto tem por base uma falsa premissa, a de que é possível realizar formação sem reflexão, sem criticidade e sem posicionamento. Como entender a vida social e histórica sem situar os interesses sociais envolvidos? Como falar do surgimento da profissão de Serviço Social no Brasil sem analisar o próprio desenvolvimento econômico, social e político do país no início do século XX, e o desenvolvimento das classes sociais? Para uma formação reflexiva e crítica, é necessário fazer todas essas conexões.

Preconizando uma formação crítica e comprometida com os valores e princípios expressos no projeto ético-político do Serviço Social, o projeto de formação profissional dos(as) assistentes sociais confronta-se com esse modelo de educação superior que fortalece a privatização e a mercantilização da educação, respalda as formações aligeiradas, prioriza a quantidade em detrimento da qualidade e implementa processos avaliativos disseminadores da competitividade entre instituições, cursos e profissionais. Nesse sentido, é fundamental reforçar a importância da universidade pública e socialmente referenciada.

[...] a universidade, eu considero que é um patrimônio, mas não um patrimônio físico só. É físico porque temos prédios, tem infraestrutura, né? Mas é um patrimônio cultural, científico, humano, que muda a vida das 
pessoas, né? Muda a vida das pessoas porque forma gente. E forma gente para mudar esse Estado. (Entrevista 9)

Além da importância cultural, social e acadêmica da universidade pública, há também o compromisso dos(as) docentes com o processo de formação de qualidade, como atestam as entrevistadas. Ao indagarmos a essas professoras sobre o que as motiva a incorporarem uma dinâmica de trabalho tão intensa e extensa, foi evidenciado, maciçamente, que isso se deve ao compromisso com a qualidade da formação profissional. Algumas professoras ressaltam que esse compromisso as levam, inclusive, a extrapolar seus limites. Nos termos de uma delas:

A questão do compromisso mesmo. Não é que eu não goste. né? Eu gosto e aí termina muitas vezes a gente se envolvendo mais do que a capacidade pessoal nos permite. E aí a gente, por uma questão de compromisso, né, com a própria profissão, com a formação, a gente termina agregando atividades mais do que na prática se pode comportar. (Entrevista 2)

Além do compromisso dos(as) docentes com o processo de formação de qualidade, é importante considerar a especificidade do trabalho docente nas instituições de ensino superior (IES), o que torna difícil mensurá-lo.

Eu acho que o nosso trabalho... o trabalho intelectual, eu acho difícil mensurar quantitativamente em horas, porque as vezes eu tô fazendo um trabalho que eu posso ficar duas horas só nele e eu me sentir extremamente esgotada, entendeu? Assim, eu não dei oito horas, mas eu, em duas horas, eu pensei muito, eu escrevi muito e eu sinto um cansaço mental. Então, acho que tem essa consideração aí a levar em conta, sabe? (Entrevista 1)

Outra especificidade do trabalho docente nas universidades são as inúmeras atividades realizadas, que vão muito além da sala de aula. 


\section{O gráfico a seguir foi construído com base nas respostas dadas ao ques- tionário, pelas dezesseis docentes participantes da pesquisa. ${ }^{11}$}

\section{Gráfico 1 - Atividades inerentes ao trabalho docente}

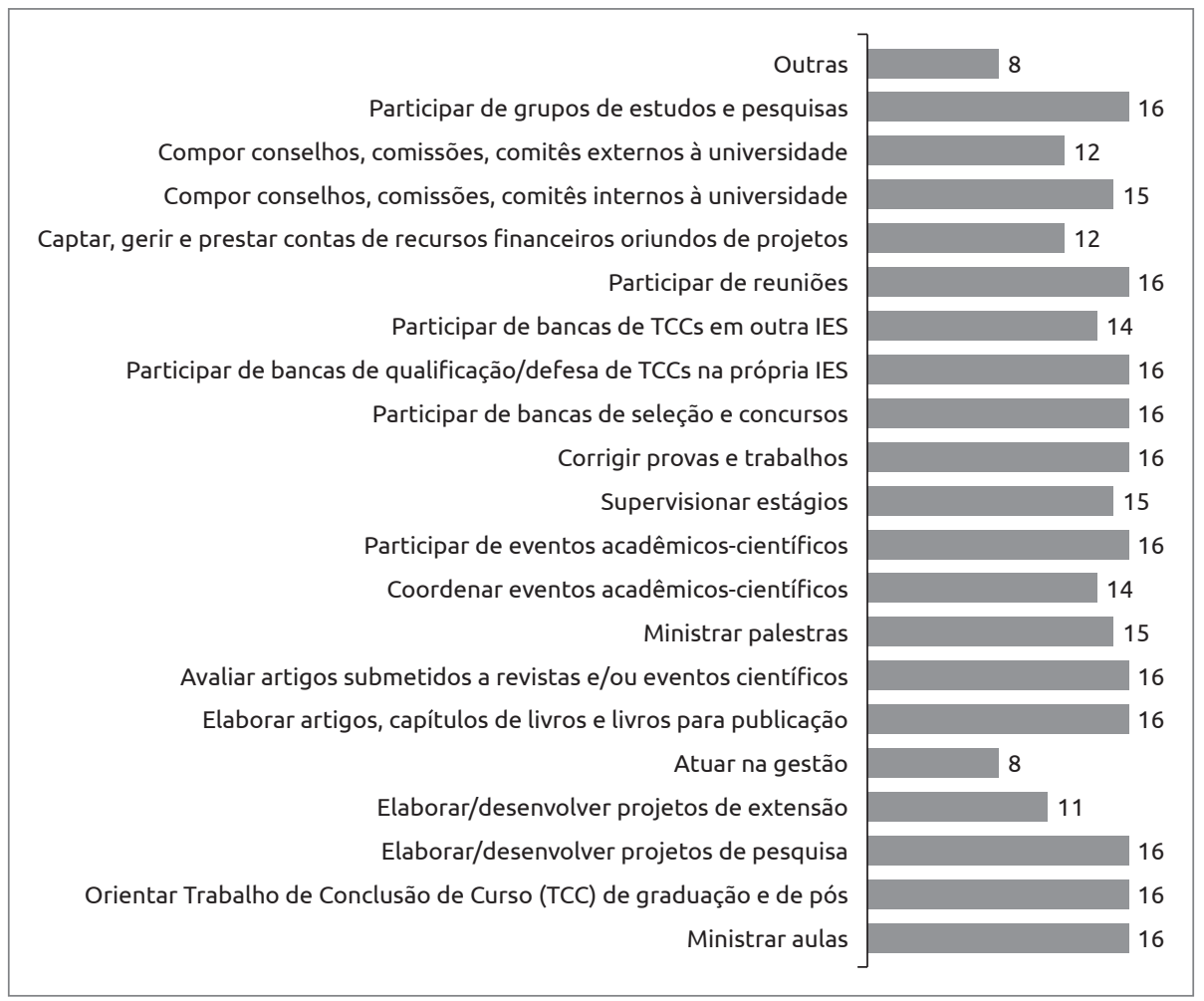

Fonte: Pesquisa, 2019.

O trabalho docente, portanto, agrega um conjunto de atividades diversificadas e que exigem elevado esforço e atualizações constantes, fato que se intensifica na conjuntura mais recente, com exigências de produção exacerbadas. No item a seguir, nos deteremos mais profundamente nas

11 Ressalte-se que a maioria das atividades relatadas é realizada por todo o corpo docente, havendo atividades específicas que não são realizadas por algumas docentes. 
particularidades do trabalho docente nas universidades pesquisadas, considerando principalmente as condições e a sobrecarga de trabalho.

\section{Condições de trabalho e sobrecarga docente: os influxos do produtivismo nas universidades potiguares}

É importante registrar que as universidades abrangidas neste estudo possuem particularidades em termos da esfera governamental a qual estão vinculadas, do seu tempo de existência e criação/composição dos seus programas de pós-graduação, suas normativas internas, quantidade de docentes e discentes, dentre outros aspectos. Dessa forma, encontramos distinções, notadamente em relação à infraestrutura, de maneira que os dados denotam melhores condições na universidade federal, sendo este ponto considerado favorável pelas docentes. Como expressa uma delas: "do ponto de vista do espaço físico, eu diria que a UFRN oferece hoje condições adequadas de trabalho" (Entrevista 15). Apesar disso, foi perceptível uma preocupação com o porvir, explicitada por docentes de ambas as instituições, conforme ilustra este comentário.

[...] nos últimos anos se vê melhorias na UFRN nos aspectos da estrutura física e recursos materiais para o cotidiano de trabalho, porém os salários e a ergonomia ainda precisam avançar na mesma proporção. É certo que essa resposta pode se fazer bem diferente nos próximos anos, dadas as previsões de cortes orçamentários na esfera da educação, muitos avanços ainda em consolidação na Universidade já estão ameaçados. (Entrevista 10)

Conforme registrado, a despeito das boas condições infraestruturais, que são fundamentais para a qualidade do trabalho docente, há necessidade de melhoria em outros aspectos relativos às condições de trabalho. Foram sinalizadas, em ambas IES, inadequações em termos de ergonomia, restrições no que se refere ao pagamento de diárias e passagens para 
participação em eventos, ${ }^{12}$ bem como ausência de reposições salariais. Acerca das condições salariais, uma entrevistada esclarece:

A gente tá aí já com largo tempo sem aumento né, [...] e o professor, além das demandas da sobrevivência, da vida cotidiana, pra você ser um bom professor demanda muito investimento. Além da área específica, a cultura, o investimento de comprar livros, outros, de ir a um cinema, de ir a um teatro, de ser alguém que participa da vida social, então... acaba que as nossas condições salariais têm muito a ver com as nossas condições de trabalho também, né. E acaba tendo um ponto de estresse. A gente vê hoje, concretamente, o empobrecimento dos docentes. [...] Então, isso interfere na tranquilidade. Você tá dando aula, fazendo pesquisa, mas preocupada com as contas pra pagar. Então, essa é uma realidade que o professor universitário não está longe disso, né, muito pelo contrário, cada dia tá chegando mais perto. (Entrevista 15)

Também foi apontada a necessidade de maior apoio técnico, pois o número de funcionários(as) é insuficiente para atender às demandas e isso tende a sobrecarregá-los(as), bem como eleva a sobrecarga das(os) docentes que precisam dar conta de alguns encaminhamentos que poderiam ser contemplados pelo trabalho de técnicos(as). Isso consome parte do tempo que poderia ser destinado à atividade intelectual, situação que afeta também aqueles(as) que assumem funções de gestão. Foram apontadas ainda a necessidade de compor um acervo de livros suficiente para atender as demandas, bem como incluir impressoras nas salas de trabalho das(os) docentes e ampliar a disponibilidade de água para beber nos diversos espaços em que trabalham, pois é comum que estes(as) trabalhem em horários que diferem do expediente administrativo. Por conseguinte, "você tem que andar com uma garrafa debaixo do braço.

12 Importa ressalvar que na universidade federal foi evidenciado que no período mais recente vem sendo adotadas algumas medidas de redução de investimentos para custear a participação em eventos. Já na universidade estadual, faz alguns anos que inexistem quaisquer investimentos desse tipo, de forma que os(as) próprios(as) docentes custeiam sua participação em eventos. 
Eu esqueço o tempo todo no carro. Então, assim, era pra ter nas salas dos professores, era pra gente ter água, eh... isso é uma coisa elementar" (Entrevista 16).

As docentes da universidade vinculada à esfera estadual enfatizaram muitos problemas no tocante à infraestrutura, aquisição e manutenção de equipamentos, disponibilidade de recursos e insumos. São imensos os problemas em termos de estrutura física, inclusive porque os espaços são, em grande parte, construções antigas que se tornaram insuficientes e inadequadas e que carecem de manutenção e reformas. Além das situações supracitadas, foram apontadas várias outras inadequações em termos de condições de trabalho na citada universidade, conforme demonstra o trecho a seguir:

[...] nós precisaríamos ter cadeiras confortáveis, salas confortáveis, um ambiente com acústica boa, um ambiente com tranquilidade, com silêncio. São coisas muito pequenas se você for pensar, né, e a gente não tem. Bons computadores, uma internet razoável que a gente pudesse se conectar, que nós pudéssemos ter... uma boa biblioteca com livros que nós pudéssemos ter acesso, então, eu acho que isso de fato nós não temos aqui na universidade. (Entrevista 5)

Porém, ao fazer uma análise da UERN, considerando suas várias fases, uma das entrevistadas ressalta que, a despeito das precariedades infraestruturais, esta universidade alcançou um elevado nível de formação dos(as) docentes. Não obstante, o número de professores(as) é insuficiente para contemplar as demandas. Outro aspecto destacado foi a questão dos salários atrasados de docentes e técnicos, bem como dos(as) demais trabalhadores(as) que são terceirizados, obstando suas condições de sobrevivência. ${ }^{13}$

13 Desde o último governo do estado do RN, Robinson Faria (2015-19), os servidores e terceirizados da UERN vêm sofrendo atrasos salariais constantes. Na gestão da governadora Fátima Bezerra (2019-), os salários, a partir do exercício de 2019, estão sendo pagos dentro do mês 
Outrossim, em ambas as unidades de formação acadêmica foi igualmente apontada pelas professoras a sobrecarga de trabalho a qual estão submetidas. A fala de uma docente é ilustrativa desta situação:

A gente trabalha muito mais que quarenta horas, a gente avança a noite, a gente avança final de semana, a gente avança a madrugada, a gente não dorme. É preparando aula, é corrigindo, é pensando textos, é pensando leituras... [...] É essa a sensação que eu tenho. Que tá sempre correndo atrás. Não sou eu só, minhas colegas também. A gente não para nunca e a gente tá sempre correndo atrás. [...] É muito pesado! É muito pesado! (Entrevista 6)

Interessante análise é apontada por uma das entrevistadas ao afirmar que o tempo precisa ser pensado também como parte das condições de trabalho.

A gente sempre pensa em condições de trabalho como algo material, mas para a atividade docente, tempo de trabalho socialmente necessário é importante. Então, se eu tenho uma cobrança que eu publique, eu tinha que ter carga horária, ser considerado espaço na carga horária para se dedicar a isso. [...] Então, se você não tem um tempo de trabalho pra você escrever, pra você pesquisar... a gente, na prática, a gente não tem tempo pra pesquisa. A gente faz pesquisa e publica e escreve artigo no horário da vida pessoal da gente. (Entrevista 16, grifos nossos)

Por conseguinte, no relato de todas as professoras, constatamos que o trabalho ocupa grande parte de suas vidas, ultrapassando a previsão contratual, embora isso seja muitas vezes invisibilizado, inclusive porque o sistema informatizado não possibilita o registro de atividades que extrapolem as quarenta horas. Além disso, existem lacunas e dissonâncias nas resoluções de distribuição de carga horária docente, a qual não

trabalhado. Contudo, até o momento (dez./2029), ainda não foram quitados os salários de novembro, dezembro e o décimo terceiro de 2018. 
contempla algumas atividades e/ou prevê tempo reduzido/insuficiente para sua efetivação, embora estas sejam exigidas, tais como a elaboração de artigos e projetos, por exemplo.

Portanto, as informações produzidas neste estudo demonstram que o trabalho se espraia pelas diversas dimensões da vida dessas trabalhadoras: o espaço da casa, o tempo do descanso e do lazer, ao impregnar-se nos finais de semana e feriados, nas férias e até no tempo que deveria ser destinado ao cuidado com a saúde, pois é comum darem continuidade ao trabalho mesmo estando com a saúde fragilizada.

Quanto tempo faz que eu não vou na praia? Tem um monte de coisa pra fazer, eu olho pro tempo, tá chovendo. Eu digo: ainda bem que tá chovendo, porque pelo menos não me dá culpa. Porque eu gostaria de tá indo pra praia, mas na praia tá chovendo; então eu vou trabalhar. [...] É a captura da subjetividade mesmo, de trabalhar, de trabalhar, de trabalhar, de trabalhar, né? (Entrevista 6)

Essa situação exaustiva é expressão das questões estruturais e conjunturais já explicitadas e de sua incorporação e às vezes até naturalização no âmbito interno das universidades.

A gente tá nos órgãos de representação sempre colocando, fazendo as críticas; mas, assim, há uma naturalização da sobrecarga de trabalho muito grande na universidade. A exploração aqui ela é, ela é mais ou menos legitimada. Eu tô dizendo assim, em sua grande maioria. (Entrevista 3)

Essa invasão do tempo de descanso está incorporada de tal forma que ocorre de a universidade lançar editais, estipular finalização de prazos em feriados e finais de semana, além da situação de alguns docentes que assumem funções que lhes demandam encaminhamentos durante as férias, tal como a orientação acadêmica cujas atribuições incluem a análise das solicitações de matrícula, as quais costumam coincidir com o período das férias coletivas de docentes. Vale ressalvar que isso vem 
sendo disseminado de forma ampliada entre a categoria profissional, a ponto de serem definidas datas de eventos e/ou finalização de prazos para envio de artigos em finais de semana ou feriados. De acordo com uma entrevistada, isso também tem contribuído para intensificar a sobrecarga de trabalho.

Eu conseguia tirar o sábado. Mas, ultimamente, assim... a gente tem... eu acho que a gente vive uma esquizofrenia de trabalho, que muita coisa tem sido feita no sábado, né? Então, eventos, geralmente é no sábado. [...] E acho que isso traz uma reflexão muito importante, assim, pra gente, que é uma decisão que tem que ser... é individual, mas tem que ser coletiva também, porque a gente tem decidido coletivamente fazer atividades no sábado. Então, quando tem um evento (estou pensando aqui num evento de Serviço Social), geralmente começa num feriado que pegue o final de semana. Porque os empregos não liberam, porque os profissionais na semana eles não conseguem... [...] Então, tudo isso demonstra uma sobrecarga de trabalho. (Entrevista 11)

Outra questão que apareceu em algumas falas é o fato de que as tecnologias de informação incrementam essa prevalência do trabalho nos diversos momentos e espaços da vida, pois tornam muito mais comum a utilização de recursos como e-mail e whatsapp para solicitação e envio de orientações, esclarecimentos de dúvidas, dentre outros.

Nosso trabalho não tem pausa. É um trabalho contínuo. Às vezes a gente... não sei se aconteceu isso com você, de estar às vezes num momento de lazer, quando você vê mensagens, né, de alunos nos perguntando coisas que são de trabalho, né. É uma orientação, via whatsapp, geralmente pelo whatsapp, que eles perguntam coisas dos projetos e que... e que eles esperam uma resposta. E eu acho muito ruim não dá, não é? Eu acho muito ruim não dá, embora esteja no meu momento de lazer, final de semana. A gente acaba respondendo. Ou seja, a gente acaba trabalhando, né? (Entrevista 7) 
Ao serem indagadas sobre o porquê do extrapolamento da jornada de trabalho e da supressão do tempo de descanso, fica perceptível que essa situação é desencadeada pelo modelo de política educacional e que isso se torna demasiado frequente no âmbito universitário.

\begin{abstract}
A primeira coisa eu acho que é a ideia de pensar... aí eu tou falando do ensino superior, é uma educação hoje que vem sendo cada vez mais pensada de uma forma mercadológica. É uma educação pensada para a criação de um processo de resultados. De resultados, mas resultados... matemáticos. [...] Isso não significa dizer que você tenha uma eficiência e qualidade no processo educativo no ensino superior, né. É uma, uma lógica que ela está concentrada ou está pautada pela... pelo produtivismo, né, pelo produtivismo eh... desse sistema que mercadoriza tudo. (Entrevista 7)
\end{abstract}

Fica perceptível nas falas das professoras que essa sobrecarga se intensifica com a pós-graduação, cujas atividades se somam às da graduação, além de exigirem maior densidade teórica e intensificarem as exigências produtivistas. Isso porque, em meio a esse processo de reestruturação capitalista, vai sendo constituído um modelo de universidade operacional, nos termos de Chaui (1999), que incorpora padrões oriundos do gerencialismo empresarial ajustado à lógica do mercado. De tal modo, "A heteronomia da universidade autônoma é visível a olho nu: o aumento insano de horas-aula, a diminuição do tempo para mestrados e doutorados, a avaliação pela quantidade de publicações, colóquios e congressos, a multiplicação de comissões e relatórios etc." (Chaui, 1999, s.p.). Os influxos desse processo podem ser observados na reflexão de uma docente:

Mas, como é que a gente tá dando conta disso? Será que a gente tá fazendo pesquisas sérias no sentido de... esse tempo por exemplo da gente fazer pesquisa é o tempo necessário de uma pesquisa que deve ser pensada, mastigada, burilada, né, analisada como ela deve ser? Então, a gente acaba espremendo o tempo da pesquisa, espremendo o tempo da pesquisa, espremendo o tempo da extensão e do próprio ensino, né? (Entrevista 7) 
É importante considerar que a maior parte dessas docentes (catorze) costuma realizar trabalho doméstico, e dedicam a essa atividade, em média, aproximadamente, duas horas e meia diárias. Isso se soma a uma extensa e intensa jornada de trabalho, conforme aponta uma delas: “[...] e muitas vezes a gente não consegue fazer as coisas aqui, e faz em casa. Quando chega em casa, por nós sermos mulheres, tem as demandas de casa" (Entrevista 3).

Ante o exposto, fica perceptível que a sobrecarga de trabalho é tão elevada que este submerge o tempo do descanso, do lazer, do sono e leva a uma sensação de que o tempo não será suficiente para dar conta de todas as demandas. "É como se a gente tivesse segurando... é um malabarismo com vários pratos ao mesmo tempo!” (Entrevista 8).

De uma forma geral, essa sobrecarga é recorrente no trabalho docente, tal como apontam diversos estudos ${ }^{14}$ que se propõem a analisá-lo na realidade brasileira. Vale destacar que essa situação tem desencadeado prejuízos à saúde (física e mental) de muitos(as) destes(as) trabalhadores(as), em decorrência da intensificação crescente do seu trabalho e subsequente redução, ou mesmo supressão, da fronteira entre vida acadêmica e pessoal (Leite, 2015).

\section{Considerações finais}

O trabalho docente integra a totalidade da formação profissional e, portanto, nele rescindem os desdobramentos do modelo de política educacional vigente, marcada pelo incremento do processo de privatização do ensino superior e da lógica da educação como mercadoria. Nessa conjuntura, o trabalho docente é permeado por condições de trabalho adversas, notadamente no que tange à sobrecarga, claramente evidenciada no contexto investigado, tanto pela quantidade de tempo efetivamente despendido para efetuar as atividades, que ultrapassa a quantidade de

14 Cf. Lima (2015), Araújo (2005) e Leite (2015). 
horas previstas nos contratos de trabalho e o espaço da academia, quanto pela intensidade do esforço exigido para a execução desse trabalho, em decorrência da complexidade e diversidade das demandas, induzida ainda mais pela elevada exigência de produção/publicação no nível da pós-graduação.

Ante o exposto, é importante rever as normas de distribuição de carga horária docente para contemplar a totalidade das atividades demandadas; discutir, inclusive com o segmento estudantil, o uso de tecnologias no cotidiano da formação profissional e seus efeitos no trabalho e nas demais dimensões da vida desses sujeitos; suprimir demandas profissionais em dias e horários de folga, inclusive no tocante aos eventos da categoria, pois, embora isso viabilize a participação de algumas pessoas, pode contribuir para naturalizar e intensificar a supressão do tempo que deveria ser destinado ao descanso, lazer e outras necessidades humanas.

Nesse sentido, almejamos que este artigo contribua para visibilizar as configurações e os percalços que permeiam o trabalho docente, bem como para instigar e subsidiar o enfrentamento dos seus desafios. Ademais, possa contribuir para impulsionar a luta pelo aprimoramento da formação profissional, como faces de um mesmo processo de responsabilização do Estado com a garantia da educação pública, gratuita, laica, de qualidade e socialmente referenciada.

\section{Referências}

ALVES, Giovanni. O novo (e precário) mundo do trabalho: reestruturação produtiva e crise do sindicalismo. São Paulo: Boitempo, 2000.

ARAÚJO, Tânia Maria et al. Mal-estar docente: avaliação de condições de trabalho e saúde em uma instituição de ensino superior. Revista Baiana de Saúde Pública, Salvador, v. 29, n. 1, p. 6-21, 2005. Salvador: SESAB, 2005. p. 6-21. Disponível em: http://rbsp.sesab.ba.gov. br/index.php/rbsp/article/view/108/990. Acesso em: 9 dez. 2019.

BEHRING, Elaine R. Brasil em Contra-reforma: desestruturação do Estado e perda de direitos. São Paulo: Cortez, 2003. 
CHAUI, Marilena. Escritos sobre a universidade. São Paulo: Editora Unesp, 2001.

CHAUI, Marilena. A universidade operacional. Folha de S.Paulo, Caderno Mais!, São Paulo, 9 maio 1999. Disponível em: http://www.cacos.ufpr.br/obras/Marilena_Chaui_ Universidade_Operacional.doc>. Acesso em: 28 ago. 2019.

CONSELHO FEDERAL DE SERVIÇO SOCIAL (CFESS). Educação como um direito e sem censura para a formação de assistentes sociais qualificados/as. 2018. Disponível em: http://www.cfess.org.br/arquivos/2018-CfessManifesta-16Enpess-Site.pdf. Acesso em: 28 ago. 2019.

ESTADÃO. Maioria das universidades federais rejeita o Future-se, plano do MEC. Disponível em: https://exame.abril.com.br/brasil/maioria-das-universidades-federais-rejeita-ofuture-se-plano-do-mec/. Acesso em: 24 nov. 2019.

FORATTINI, Cristina D.; LUCENA, Carlos. Adoecimento e sofrimento docente na perspectiva da precarização do trabalho. Laplage em Revista, Sorocaba, v. 1, n. 2, p. 32-47, 2015. Disponível em: http://www.laplageemrevista.ufscar.br/index.php/lpg/article/ view/19/369. Acesso em: 8 jun. 2018.

G1 ECONOMIA. Reforma da Previdência: entenda a proposta aprovada ponto a ponto. 2019. Disponível em: https:/g1.globo.com/economia/noticia/2019/10/22/reforma-daprevidencia-entenda-ponto-a-ponto-a-proposta-aprovada-em-2o-turno-no-senado.ghtml. Acesso em: 24 nov. 2019.

ILHÉU, Taís. Future-se: projeto do MEC está aberto à consulta pública. Disponível em: https://guiadoestudante.abril.com.br/universidades/future-se-projeto-do-mec-estaaberto-a-consulta-publica/. Acesso em: 24 nov. 2019.

JÁCOME, Igor. UFRN, IFRN e Ufersa têm cortes de R\$ 101 milhões no orçamento. Disponível em: https:/g1-globo-com.cdn.ampproject.org/v/s/g1.globo.com/google/amp/ rn/rio-grande-do-norte/noticia/2019/05/03/ufrn-ifrn-e-ufersa-tem-cortes-de-r-101milhoes-no-orcamento.ghtml?amp_js_v=0.1\#referrer=https\%3A\%2F\%2Fwww.google. com\&amp_tf=Fonte\%3A\%20\%251\%24s\&ampshare=https\%3A\%2F\%2Fg1.globo. com\%2Frn\%2Frio-grande-do-norte\%2Fnoticia\%2F2019\%2F05\%2F03\%2Fufrn-ifrne-ufersa-tem-cortes-de-r-101-milhoes-no-orcamento.ghtml. Acesso em: 3 maio 2019.

LEITE, Janete L. Produtivismo acadêmico e adoecimento docente: duas faces da mesma moeda. In: FERREIRA, André Vasconcelos et al. (orgs.). Precarização do trabalho e saúde docente nas universidades públicas brasileiras. Fortaleza: Eduece, 2015.

LIMA, Daniele G.; LIMA, Rita de Lourdes. A EC-95/2016 e a educação superior no Brasil: a materialização perversa do Novo Regime Fiscal. Universidade e Sociedade, Brasília, ano XIX, n. 63., p. 46-57, 2019. Disponível em: https://www.andes.org.br/img/midias/0ec5f9a c2d526c8cf77a1ad0eeadc254_1549480264.pdf. Acesso em: 26 ago. 2019. 
LIMA, Rita de Lourdes. Docência e Serviço Social: condições de trabalho e saúde. Temporalis, Brasília, ano 16, n. 31, 2016. Disponível em: http://periodicos.ufes.br/ temporalis/article/view/12200/10108. Acesso em: 28 ago. 2019.

MORENO, Ana Carolina. MEC reformula proposta do Future-se e diz que lançará nova consulta pública até o dia 28. 2019. Disponível em: https://g1.globo.com/educacao/ noticia/2019/10/18/mec-reformula-proposta-do-future-se-e-diz-que-lancara-novaconsulta-publica-ate-o-dia-28.ghtml. Acesso em: 24 nov. 2019.

MUSTAFA, Patrícia S. Estado capitalista brasileiro: análise dos direitos sociais em tempos de ortodoxia neoliberal. Katálysis, Florianópolis, v. 22, n. 1, p. 100-109, jan./abr. 2019. Disponível em: https://periodicos.ufsc.br/index.php/katalysis/article/view/198202592019v22n1p100/39118. Acesso em: 28 ago. 2019.

NETTO, José Paulo; BRAZ, Marcelo. Economia política: uma introdução crítica. São Paulo: Cortez, 2006.

\section{Sobre as autoras}

IANA VASConcelos - Doutora em Ciências da Saúde.

E-mail: ianavasconcelos@bol.com.br

RITA DE Lourdes DE Lima - Doutora em Serviço Social, professora do Programa de Pós-Graduação em Serviço Social.

E-mail: rita.pires2@gmail.com 